exhibit of cacti and other succulent plants which was shown by Mrs. A. Sherman Hoyt, of Pasadena, California. The collection of living plants was arranged against a painted scene of the Mohave Desert, and the whole exhibit was a presentation of the desert flora of Southern California. At the close of the Show, Mrs. Sherman Hoyt very generously presented the collection of living plants to Kew, together with the painted desert scene and the rock and sand which she had brought over from California. Since it was impossible to make an adequate display of her exhibit or to make use of the very beautiful painting in any of the houses at Kew, Mrs. Sherman Hoyt most generously offered to build a special house for the display of her plants with the background. In the house, now completed and planted, the desert scene occupies the semi-circular wall of the apse, and in the foreground is a representation of the desert in conformity with the painted background. The stone which has been used for building up the foreground is old red sandstone from Dunster, Somerset, and matches remarkably closely both in colour and structure the Californian rocks shown in the picture. Cacti and other succulent plants have been placed among the rocks in positions as near as possible to those in which they are found in their native home, and the whole effect makes a remarkably striking picture, since the rocky foreground blends so naturally with the painted desert scene behind that it is by no means easy to detect any break between the actual living plants and those shown in the background. The house was opened to the public on March 24 .

\section{India and Babylonia}

Tre discoveries at Tell Asmar (Eshnunnu or Ashnunnak), announced by Dr. H. Frankfort in his letter to the Times of March 26, constitute an addition of no little importance to the evidence linking up the early civilisations of Mesopotamia and the Indus valley, especially if his conjectural relation of the new finds to the culture of Mohenjo Daro should be confirmed by subsequent investigation. The excavations of the Oriental Institute of Chicago on the site of private houses of the age of the Dynasty of Akkad (c. 2550 B.c.) on the northern outskirts of the Tell have brought to light two seals, of which the character points unquestionably to an Indian origin. One, a cylinder seal, shows a design of a procession of animals, elephants and rhinoceros with crocodiles, which in subject and convention is both alien to Mesopotamia and referable to the Indus civilisation; while the second is of more common Indian form, a square stamp seal with a pierced knob on the back, and bearing a design of concentric squares which does not appear elsewhere in Mesopotamia, but occurs on similar seals at Mohenjo Daro. Further evidence pointing in the same direction has been found in the form of etched carnelian beads resembling Indian specimens, kidney-shaped inlays of bone identical in shape with some in shell from Mohenjo Daro, and two sherds of pottery showing a decoration with knobs, unknown in Mesopotamia, but also occurring at Mohenjo Daro. Certain distinct. ive features in the seals, however, lead Dr. Frankfort to think that either they belong to a slightly earlier or later phase of Indian civilisation than that at Mohenjo Daro or they may have come from another site within the same cultural area, the latter alternative being the more probable.

\section{Bird-ringing in Great Britain}

THE banding or ringing of birds is now accepted as the established technique for elucidating migratory and other movements, and Mr. H. F. Witherby and the British Birds scheme are to be congratulated upon the success with which they have kept the system alive and increasingly flourishing in the British Isles. During 1931, more British birds than ever were marked with identification rings, 29,554, and this brings the grand total since the beginning of the scheme in 1909 to 316,955 (British Birds, March 1932, p. 286). Recoveries vary greatly amongst the different species: the highest percentages are shared by two birds of prey, the peregrine falcon $(23.3$ per cent) and the merlin (21.8 per cent), and these figures suggest the intensity of destruction which overtakes such birds at the hands of game-preservers, for even the innocent kestrel is represented by 49 returns out of 494 ringed. At the other end of the scale stands the blackcap, the 517 ringed individuals of which gave not a single return, and for all the warblers and even many of the finches the recoveries are very meagre. Of 496 nightingales only 2 have been handled again, and of 507 arctic terns only one. It is obvious that a great deal of labour goes unrewarded in ringing birds ; 22,943 swallows have yielded only $163(0 \cdot 7$ per cent) returns, but the returns have brought out new facts regarding the range of the southward migration and the return of the birds to the locality of their birth. More curious still, of 37,225 songthrushes, only 481 or 1.4 per cent have been found again.

\section{The Nature of Carpels}

IN a preliminary notice (Bull. Classe des Sci. (Acad. Roy. de Belgique) 5e Série, tome 17, 1931), Grégoire has criticised the view of the foliar nature of carpels, and in a fuller treatise he proposes also to extend the argument to the comparison of stamens with leaves, and, in fact, of the flower with a vegetative bud. His criticism is based on ontogeny; he points out that when carpels are formed, they do not appear as lateral structures on the floral axis, and the apex of the latter can never be recognised as still persistent in the centre of the flower. Further, he considers that the margins of the carpellary upgrowths do not meet and fuse marginally as is usually supposed, but are merely the appearances due to the upward extensions of a split in the tissues of the lower part, as this expands to form the cavity of the ovary. Most botanists agree, however, that the comparative morphology of vegetative and reproductive shoots supports the general view of the homology of vegetative bud and flower, but the changed type of growth has so altered the floral parts that, the nearer one passes towards the centre of the flower, the more difficult does it become to press detailed comparisons. 